\title{
Resistências frente à medicalização da existência
}

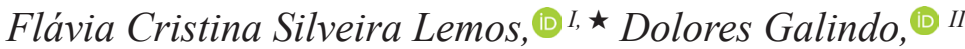 \\ Renata Vilela Rodrigues, (1I Evelyn Tarcilda Almeida Ferreira ${ }^{(1)}$ I \\ ${ }^{I}$ Universidade Federal do Pará, Belém, PA, Brasil \\ "I Universidade Federal de Mato Grosso, Cuiabá, MT, Brasil \\ Resumo
}

\begin{abstract}
Este artigo tem o objetivo de interrogar as práticas de medicalização dos corpos, no presente, e descrever alguns movimentos, associações e entidades que participam das resistências às práticas medicalizadoras. Busca-se pensar quais são os efeitos desses movimentos, quais são suas pautas e preocupações e como articulam reivindicações e críticas, diante do crescente processo de medicalização das existências e da sociedade. Aborda-se a constituição do objeto e a problemática do trabalho, a partir de Michel Foucault e das contribuições produzidas nas aulas, conferências e publicações realizadas, no Brasil. As resistências são apresentadas, descritas e analisadas no limite do contexto nacional, apesar de também serem pensadas em uma esfera internacional, mas não é o caso neste estudo. A presença das psicologias é marcante em boa parte dos movimentos de resistência e, em vários casos, se tornou a base de crítica à medicalização, nas últimas décadas com atuação relevante neste âmbito político e social.
\end{abstract}

Palavras-chave: resistências; movimentos sociais; medicalização; Brasil; Psicologia.

\section{Resistance against the medicalization of existence}

\begin{abstract}
This article aims to interrogate the practices of medicalization of bodies, in the present, and to describe some movements, associations and entities that participate in the resistance to the medicalization practices. It seeks to think what are the effects of these movements, what are their patterns and concerns and how articulate claims and criticisms, in view of the growing process of medicalization of existences and society. The object's constitution and the labor problematic are discussed, starting with Michel Foucault and the contributions made in lectures, conferences and publications held in Brazil. Resistances are presented, described and analyzed within the limits of the national context, although they are also thought of in an international sphere, but this is not the case in this study. The presence of psychologies is marked in most of the resistance movements and, in several cases, has become the basis of criticism to medicalization, in the last decades with relevant action in this political and social.
\end{abstract}

Keywords: resistances; social movements; medicalization; Brazil; Psychology.

\section{Introdução}

Pretende-se, nesse artigo, pensar as resistências às práticas de medicalização da vida. Em primeiro lugar, definindo medicalização com as contribuições de Michel Foucault e de alguns aportes de Nikolas Rose, entre outras referências citadas, às quais ofertam ferramentas importantes desta analítica. Sabe-se que seria possível trazer outros autores para esta problematização do objeto histórico em tela; todavia, houve uma escolha conceitual, realizada neste artigo e por ele delimitada.

Em um segundo momento, o texto aborda algumas práticas concretas de resistência à medicalização, na Psicologia, considerando a articulação de associações de diversos grupos organizados em frentes e fóruns. Diante deste escopo de trabalho proposto, outras práticas de resistência poderiam ser descritas, mas nos limitamos a dar destaque a algumas específicas, selecionadas na Psicologia brasileira, nos últimos anos.

O artigo também aborda uma discussão metodológica das práticas em Michel Foucault (1975/1979), em especial nos estudos históricos genealógicos dos processos de medicalização e das resistências nas relações móveis de poder e saber dos acontecimentos. O artigo é finalizado

\footnotetext{
^Endereço para correspondência: Universidade Federal do Pará. Rua Augusto Corrêa, 01, Guamá, Belém, PA - Brasil. CEP: 66075110. E-mails: flavazevedo@bol.com.br,dolorescristinagomesgalindo@gmail.com, renata_vilelarvr@ hotmail.com, evyalmeida@gmail.com

Os dados completos das autoras encontram-se ao final do artigo.
}

com o objetivo de pensar aberturas e possibilidades de uma problematização à medicalização, em atenção às precauções metodológicas de Michel Foucault, na analítica do poder, saber e subjetivação quanto à positividade do poder, tanto na esfera das prescrições normalizantes quanto no que tange aos seus efeitos na regulação dos corpos e produção de saúde.

Foucault (1975/1979, 1976/1988) sempre deixou claro que não analisava o poder apenas como negatividade, e sim que buscava operar com uma perspectiva também positiva e produtora das relações de poder na construção das práticas. Deste modo, considerando a vertente da analítica de poder, Foucault (1975/1979) ressalta que a medicalização não está em oposição à política de saúde, mas faria parte do dispositivo de governo da vida, o qual visava forjar corpos saudáveis e supostamente seguros.

\section{Definição de medicalização por práticas de objetivação}

Para Ortega (2008), o termo medicalização surge, no início da década de 1960, no campo da sociologia da saúde, em um forte aumento da definição de diversas questões tensas do cotidiano, mais limitadas à clave medicalizante, de forma reducionista. Ortega transitou conceitualmente, considerando a produção de Illich, o qual asseverava o quanto havia uma extensão do controle profissional da saúde por meio dos cuidados dispensados às pessoas adoecidas ou ainda para as que não teriam adoecido. 
Os membros dos supostos grupos que não adoeceram, porém teriam tendências a adoecer, seriam parte de outro segmento a ser medicalizado. Tratamos aqui de pessoas saudáveis, as quais gostariam de vivenciar uma promoção intensiva de saúde, sendo que as mesmas seriam submetidas a modos mais específicos e singulares de medicalização. Em nome do aumento da qualidade de vida, estes grupos estariam dispostos a experimentarem tecnologias leves por meio de diversos saberes e poderes da promoção de saúde em uma perspectiva coletiva de uma medicina personalizada (NOVAS, 2006). Alguns grupos desejam potencializar a saúde ao ponto de chegarem a uma alta performance de saúde, em uma nova manifestação da medicalização da vida. Com efeito, Ortega (2008) traça todo um escopo rico e complexo dos processos de medicalização. $\mathrm{O}$ autor descreve como foi constituída uma cultura somática medicalizada, tanto em uma dimensão social quanto nas dimensões históricas, econômicas e políticas.

A cultura medicalizante passou a funcionar de um modo dependente dos saberes de especialistas biomédicos, pedagógicos, jurídicos e psicológicos com o propósito da criação de um campo valorativo da saúde e do cuidado meticuloso de um corpo saudável e seguro. Conforme observava Foucault, na década de 1970, a medicalização funcionaria pela promoção da saúde, pela prevenção e por outras vias de governo das condutas, concomitantemente e adjacentes à política de saúde mental e coletiva, tais como: na educação, na justiça, nas políticas sociais, na família e na cidade (FOUCAULT, 1975/1979).

Conforme Foucault (1975/1979; 1976/1988; 1977/2008a), a medicalização produz normas de vida, regras de higiene, critérios de limpeza, técnicas terapêuticas, práticas de diagnósticos e tratamentos, uma oferta de medicamentos, um âmbito de programas e projetos para curar e prevenir doenças. Trata-se de um conjunto amplo de práticas constitutivas da expansão de saúde e vida, não apenas face às doenças, mas especialmente voltadas à gestão dos riscos, perigos e performances. A medicalização não é apenas relativa ao fenômeno de uma prática limitada ao ato de medicar e definida pela ingestão e prescrição dos medicamentos de forma indiscriminada.

A medicalização opera com a promoção de saúde, a prevenção de doenças, e pode atuar sobre curas e tratamentos hospitalocêntricos. Porém, o processo de medicalização pode, ainda, se materializar pela incitação de condutas com vistas à expansão da saúde, e pode agir insuflando os corpos a organizarem e a compensarem supostas incapacidades e, até mesmo, a aumentarem os rendimentos e desempenhos, independentemente das doenças e tendências à aquisição de doenças.

Foucault (1975/1979) apontou o funcionamento de uma medicalização chamada de autoritária contra grupos considerados indigentes, os quais eram submetidos às internações forçadas, aos tratamentos muito invasivos e de medicações bastante intensivas, etc. Mas Foucault salientava, também, outro tipo de funcionamento da medicalização, a qual foi definida por ele como soft, voltada às classes mais abastadas, composta por psicoterapias, exercícios físicos, meditações, dietas e massagens, por exemplo.
Vale destacar que a medicalização não seria apenas da ordem da repressão negativa de um poder coercitivo, baseado em leis sobre os corpos. O poder teria uma positividade de operar por táticas e normas e não apenas por leis e imperativos de dominação das condutas. Há uma perspectiva de seguridade social, na oferta de medicalização, ou seja, é parte de um sistema de proteção e cuidado na esfera da garantia dos direitos, à qual foi descrita nos cursos Segurança, território e população (FOUCAULT, 1977/2008a) e Nascimento da Biopolítica (FOUCAULT, 1979/2008b).

Seguindo esta linha analítica do poder, de acordo com os estudos de Foucault (1975/1999), vale mencionar o quanto o poder, o saber e a subjetivação estão articulados; onde há poder há resistência, e poder não é só aquilo que diz não. Também não se limita à obrigação de alguém fazer algo, no âmbito legalista, apenas. As práticas de poder são dinâmicas e relacionais, operam por meio de ações sobre ações, força em agenciamento com outras forças. Poder não é uma composição dual de forças opostas; as relações de poder são múltiplas e sempre operam entrecruzadas.

Portanto, neste âmbito trabalhado acima, as práticas medicalizadora e não medicalizadora não poderiam ser estudadas e trabalhadas de forma simplista, por exemplo, pois é justamente a partir da produção de saúde e da reivindicação de maior seguridade de direitos que se aciona a possibilidade de uma materialidade da medicalização se generalizando como modo de existência. Desse modo, não se trata de ser contrário à medicalização, em uma lógica binária de oposição de ser contra ou a favor de.

\section{A medicina social e os processos de medicalização da vida: resistências}

A racionalidade medicalizante nos atravessa em termos de um processo de subjetivação, possibilitando tanto a ação do cuidado quanto a dimensão da seguridade social em políticas de prevenção e tratamento em saúde. Medicalizar pode também ser uma prática de controle social e ainda se tornar autoritária. Foi neste sentido que Foucault (1975/1979, 1976/1988, 1975/1999) declarou o quanto há um paroxismo na atenção em saúde pela medicalização, pois, ao mesmo tempo, há mecanismos de proteção acoplados aos de controle e segurança da sociedade.

No bojo dessa questão paradoxal, é possível pensar o plano complexo da existência e das práticas sociais a serem problematizados sem moralismos e sem lógicas de oposição binárias e reducionistas. Portanto, ser saudável e ser controlado são faces da mesma moeda nos efeitos dos processos de medicalização dos corpos e da sociedade (NOGUEIRA, 2003).

Por isto, a analítica do poder nos auxilia a refletir sobre a medicalização, na medida em que poder é uma multiplicidade de forças heterogêneas, formada por um conjunto de práticas correlatas. $\mathrm{Na}$ dinâmica do poder sempre se é governado e se governa, de acordo com Foucault (1977/2008a); contudo, as dimensões política, ética e estética da existência imprimem a possibilidade da interrogação sobre as práticas de governo e os efeitos das mesmas historicamente sobre os corpos, permitin- 
do resistências. O governo das condutas, para Foucault (1977/2008a), implica uma agonística de enfrentamento permanente entre forças, diante da qual é relevante se perguntar: em que medida se está disposto a ser governado de uma determinada forma e até que ponto a busca de saúde será realizada e com que intensidade, quando poderá vir atrelada ao aumento de controle social paralelamente?

Resistir à medicalização também é operar nos entremeios dela para poder tecer transformações no bojo mesmo das práticas de governo em que estamos submetidos. Na atualidade, quando buscamos saúde seremos, de algum modo, medicalizados. Todavia, é possível analisar de que maneira e por quais tecnologias e; ainda, em que medida e, por quanto tempo, por meio de quais saberes e poderes. Portanto, a questão é bem mais complexa do que uma mera escolha entre medicalizar ou não, pois envolve um conjunto de forças, atualizando-se em práticas heterogêneas concretas (FOUCAULT, 1975/1979). Porém, é oportuno salientar que uma intervenção em saúde não é apenas potencializadora da vida, pois, quanto mais segurança e proteção nós demandamos, mais controle e o solicitamos, concomitantemente.

O controle opera na esteira da proteção, em imanência de forças, pois não há tratamento, cuidado e atenção em saúde que não passe por algum nível de controle do corpo e da subjetividade, em certa medida e por um determinado especialismo e tempo. Organizar políticas de saúde coletiva e mental, educar em saúde e gerenciar tecnologias de cuidado implica governar condutas e também as resistências realizadas pelas condutas de resistências decorrentes. Onde há poder há resistência sempre; quando há poder também haverá saber e algum processo de subjetivação, ou seja, de uma política da verdade subsidiando um conjunto de modos de viver, sentir, pensar, agir e se relacionar.

Neste sentido, é relevante e crucial analisar as práticas realizadas pelas organizações agenciadoras de algumas formas mais recorrentes e em expansão no plano da medicalização, tais como: a maneira de funcionamento das corporações farmacêuticas e das pesquisas científicas, a produção da biomedicina-biotecnologia e o marketing das terapias e dos medicamentos, os quais articulam densas redes de saber-poder que, por sua vez, atravessam nossos corpos, nosso pensar e sentir, nossas subjetividades. A modulação neurobioquímica e terapêutica da vida se tornou um crescente mercado, entrecruzada com a cidadania, no plano dos direitos biológicos, sociais, econômicos, culturais e psicológicos, no plano do fazer viver até o do deixar morrer.

A construção do diagnóstico, no que tange às avaliações para o exercício do cuidado, baseia-se em indicadores psicométricos, biológicos, bioeconômicos, entre outros, para forjar devolutivas e laudos, na medicalização amparada em saberes criados por meio dos olhares de avaliação e geradores dos efeitos de poderes relacionados aos encaminhamentos. Avaliar, examinar em verdade, hierarquizar os saberes e poderes, privilegiar modos de diagnosticar e tratar, articular linhas de cuidado em saúde com as de controle social em nome da segurança são formas contemporâneas de forjar o percurso medicalizador das condutas.

Nos novos parâmetros medicalizantes do social, os médicos ainda são agentes importantes, na atualização higienista e terapêutica, mas seu papel se tornou menor, já que é partilhado com as empresas farmacêuticas, por outros profissionais e uma por uma variedade de saberes correlatos e com efeitos variados. A medicalização, agora, estende-se também à relação entre empresas farmacêuticas, médicos, alguns grupos de psicólogos mais ligados às correntes cognitivo-comportamentais e neuropsicológicas, bem como agencia consumidores de uma série de discursos e produtos em nome da saúde. A medicalização também já não está restrita somente ao âmbito da política de saúde e pode se materializar em uma série de práticas mercadológicas e judicializantes cotidianas, suplementares ao cuidado meticuloso dos corpos individuais e com fins da regulação populacional, simultaneamente.

Por meio do marketing das empresas farmacêuticas, os medicamentos prometem uma estabilização de sentimentos, humores e ações, em um contexto social e político-econômico de encomendas voltadas a uma constante aceleração de cada ato e pensamento, com vistas ao mercado do investimento na gestão da saúde. O marketing é propulsor, ainda, da medicalização da postura corporal, dos exercícios físicos, e incita ao empresariamento dos corpos, mensurando a aferição de performances num fazer viver em longevidade, condições de desempenho e competição (ANGELL, 2007).

Nas práticas de medicalização atuais, as pessoas se orientam por critérios de biossegurança e procuram gerir riscos, através de dispositivos de vigilância e controle disponíveis; se apropriam de uma busca de previsibilidade em relação aos quadros clínicos futuros e, com isso, suas existências são moduladas pela incerteza e busca frenética de um acompanhamento dos níveis de confiança e tranquilidade. Na gestão da insegurança, a prevenção, aliada à precaução, se mostrou um instrumento bastante efetivo, haja vista possibilitar a medicalização da probabilidade futurológica do desenvolvimento de alguma patologia e mesmo do alcance de um ideal de normalidade pela busca do corpo e saúde, na racionalidade hiperpreventiva (ROSE, 2007/2013).

A ideia de hiperprevenção, para indicar tanto a lógica preventiva baseada nos cálculos de riscos quanto à lógica preventiva pautada por medos de ameaças que sequer chegam ao que viria a ser a precaução. As técnicas medicalizantes de modulação dos desempenhos, com o uso de drogas variadas e exercícios diversos, enquanto tecnologias de si objetivam aumentar a produção econômica e a docilidade política. A efetuação da medicalização, que pode estar articulada à farmacologização, mas não se reduz a ela, requer um agenciamento contínuo de subjetividades que se configuram como "kits de existências" preventivos, visando à redução de riscos e perigos, tentando extinguir o campo de incertezas dos adoecimentos futuros (CAPONI, 2009). 
Para Rose (2007/2013), a medicina vem modulando nossos regimes éticos, nossas relações conosco, nossos julgamentos do tipo de pessoa que queremos ser e o tipo de vida que queremos levar. Prescrever e incitar esses estilos de vida passa a ser um negócio no empreendedorismo atual, na oferta de práticas de governar pelo medo de adoecer e de perder a vida, cuja efetividade requer subjetivações pautadas pelo medo. Ao operarmos como categoria "em constante perigo", estamos entrando no espaço futurológico das probabilidades. Foucault (1975/1999) já apontava ser uma das principais características da biopolítica uma visão voltada para o futuro. Rose (2007/2013) aponta a constituição dos selves neuroquímicos e das cidadanias biológicas, designadas a partir da emergência do neoliberalismo empreendedor e da medicalização como parte da engrenagem empresarial da vida, inclusive de movimentos em prol de novas terapêuticas e/ou liberação de fármacos em fase de ensaios clínicos, testes genéticos e tantas formas de medicalização exacerbada na sociedade contemporânea (MARTINS, 2008).

A medicalização está inserida nos mais diversos e múltiplos âmbitos de nosso cotidiano. Seria ingênuo pensá-la como um impacto exclusivamente negativo, vistos os importantes avanços da medicina, genética, alimentação, exercícios físicos e esportes, farmacologia e biossegurança. Contudo, salientemos que estamos cada vez mais propensos a pensar a vida e suas nuances de forma extremamente reducionista, a exemplo da aposta de que o monitoramento das atividades cerebrais permite a prescrição de medicamentos precisos para controlar variações neuroquímicas subjacentes. Novas tecnologias de saúde são organizadas na imanência, ou seja, na correlação ao acaso de forças com as mutações do mercado, com as transformações das famílias, com os efeitos ecológicos dos impactos ambientais, com as alterações da política e com a atualização das relações sociais e culturais. Essas modulações de subjetivação se organizam como forças em agenciamentos coletivos, os quais operam por correlações sem causalidade e sem linearidade, na esfera dos acontecimentos que se cruzam e se conectam como teias com privilégios de entradas e saídas das suas linhas de composição por marcadores acentuados pelas desigualdades sociais e econômicas.

\section{Jogos de poder e saber na medicalização, no Brasil: percursos e especificidades}

As lutas diante dos interesses internacionais e nacionais e em face da privatização, da precarização dos serviços de saúde e do sucateamento dos equipamentos são cada vez mais travadas no cotidiano, ao longo dos últimos anos, no Brasil. Os planos de saúde, muitos dos quais provenientes de outros países vêm crescendo sob uma tendência hospitalocêntrica, pautada na prescrição de exames, de cirurgias e de medicamentos, agindo em uma racionalidade ancorada, em grande parte, em propostas medicalizantes.

Como enfrentamento a esses acontecimentos, foram criadas várias resistências, tais como as do Fórum sobre Medicalização da Educação e da Sociedade, criada em novembro de 2011, durante a realização do II Seminário Internacional sobre Educação e Medicalização, em São Paulo. Núcleos foram formados em todo o Brasil e movimentaram resistências em relação aos projetos de lei que propunham ampliação dos processos de medicalização; o movimento também colocou na mídia o debate, que antes era blindado, de certo modo. Além do mais, realizou seminários e rodas de conversa em todo o país sobre o tema, articulando-se igualmente com outros movimentos, conselhos profissionais, universidades, sindicatos e organismos internacionais contrários à intensificação da medicalização da educação e da sociedade. É formado por 67 entidades signatárias e 19 núcleos, contemplando todas as regiões do Brasil. Os Conselhos de Psicologia e psicólogos participam ativamente, por meio dos núcleos e da secretaria executiva do Fórum, desde sua criação até o presente.

O Fórum tem uma grande presença de psicólogos, em todo o Brasil, pertencentes às políticas públicas, às universidades e aos cargos de gestão nos mais variados níveis, atuando concomitantemente, em várias associações de pesquisa, publicando notas, intervindo nas mídias, realizando articulações internacionais com movimentos semelhantes da Psicologia e áreas afins. A área de educação e saúde vem ganhando imensamente com as intervenções do Fórum sobre medicalização no país. Os desdobramentos na Psicologia operam no aumento da discussão, em contextos os mais diversos de debates e estudos sobre os processos de medicalização. Os resultados das resistências do Fórum ocorrem na quebra do bloqueio de explicitação dessa pauta, no cenário político brasileiro.

A visão empresarial de saúde, na atualidade, tem efetuado forte pressão para desmantelar as políticas públicas de saúde e colocado novos desafios para os movimentos sanitaristas, antimanicomiais, sobre medicalização e patologização da existência. Assim, movimentos sociais populares, sobretudo os sanitaristas, de saúde coletiva e associações lutaram para construir um sistema de saúde baseado em direitos sociais e universais, em uma perspectiva comunitária e de produção de singularização no atendimento e na oferta da atenção.

Outra organização em que houve participação protagonista da Psicologia brasileira foi a de formação da Frente Nacional Drogas e Direitos Humanos, criada em 2012, como uma resistência à proposição do Plano Crack, ainda no primeiro mandato da outrora Presidente Dilma Rousseff. Este acontecimento ocorreu em plena realização da XIV Conferência Nacional de Saúde, a qual se posicionava contrária a esse plano e apontava para o fortalecimento da Política Nacional de Redução de Danos e das Redes de Atenção Psicossocial (RAPS), com o aumento de Centros de Atenção Psicossociais e sua articulação com os Consultórios de Rua, na relação de comunidades, territórios, famílias e equipamentos de saúde, de educação, de assistência social e de trabalho pelo projeto de economia solidária e habitação.

O objetivo da Frente, composta por 53 entidades nacionais, é a luta pela dignidade, cidadania e direitos humanos na política sobre drogas. Desde 2010, no âmbito do executivo brasileiro, a questão das drogas se tornou uma 
pauta importante, baseada no combate ao crack, assentada na lógica de internação e estigmatização dos usuários. É possível afirmar uma separação entre a medicalização no âmbito dos psicofármacos e diagnósticos e a indústria da criminalização e da denominada guerra às drogas. Nas duas há lei regulando, mas na segunda há uma incidência maior da medicalização, acrescida de punições e encarceramentos, além de patologização mais intensa.

Para Foucault (2008b), a biopolítica como gestão da vida andou junto com o liberalismo como estilo de vida, visando mais a uma subjetividade empresarial do que à do sujeito de direitos, apesar de estabelecer conluios e entrecruzamentos entre as duas na esfera do mercado da saúde, em uma economia política neoliberal, especialmente. A medicalização, tanto a autoritária quanto a chamada soft, sustentou a expansão da racionalidade privada de assistência à saúde, gerando incidência sobre as resistências à medicalização apropriada pela lógica privada, no Brasil e em outros países, sobretudo nos últimos anos.

$\mathrm{O}$ que vem sendo reconhecido como crise de uma política pública de saúde encontra respaldo na crise do modelo do bem-estar social, que, na década de 1970, desenvolveu-se na Europa e, mais incisivamente, no Brasil da última década do século XX em diante. O surgimento da arte neoliberal de governar organizou-se pela ruptura com a oferta de políticas públicas estatais e deslocou a figura do Estado para a regulamentação da lógica privada e/ou público-privada.

A proliferação de especialistas e de empresas que participam dessas práticas é intensiva hoje. Há, na atualidade, uma forte disputa de interesses, de corporativismos profissionais, de concorrência entre empresas, de fragmentações dos movimentos sociais nas lutas, da constituição de comitês e conselhos representativos para a tomada de decisão, com a participação de cidadãos, fundações, organizações não governamentais, bancos, corporações multinacionais e uma variedade de empresas que participam do jogo político e econômico da produção da saúde, ora usando discursos medicalizantes, ora os colocando à parte ou mesmo os criticando. A saúde entra nas prateleiras de um grande e altamente lucrativo mercado da vida.

É nesse campo que entra a participação de psicólogos na criação da Frente Nacional contra Privatização da Saúde, composta por diversos fóruns estaduais em torno da luta por uma atenção à saúde totalmente pública, estatal e de qualidade, reunindo 15 fóruns estaduais e onze municipais. A Frente Nacional contra a Privatização da Saúde vem atuando contra formas de desmantelamento do SUS, como a transferência da gestão para as Organizações Sociais (OS), a precarização dos serviços e dos trabalhadores da saúde e a Empresa Brasileira de Serviços Hospitalares (EBSERH).

O campo privado e a lógica hospitalocêntrica de saúde vêm se expandindo no bojo do aumento da medicalização e por meio dele. Contudo, a medicalização não se limita à racionalidade privada de saúde, já que também opera pela promoção, prevenção e pelas terapias alternativas. A me- dicalização ocorre na educação, nas políticas sociais e na justiça, em coextensão com as práticas de promoção e tratamento, na política de saúde, seja pública e/ou privada.

O Movimento de Luta Antimanicomial está ligado a outros movimentos sociais, que surgiram no contexto da lenta abertura política do Brasil durante o regime militar. Esse movimento é crucial para a problematização da medicalização, na medida em que interroga a internação de pessoas diagnosticadas em hospitais psiquiátricos, questiona a prescrição indiscriminada de medicamentos psicotrópicos, luta contra a internação compulsória de usuários de drogas, reivindica a ampliação de saúde mental na atenção básica, de caráter preventivo na política nacional de redução de danos dos usos de drogas de base territorial e comunitária.

A Associação Brasileira de Saúde Mental (ABRASME) foi criada em 2007. Está sediada em Florianópolis e possui representações em mais de dez Estados do Brasil. Iniciou-se com cerca de 200 fundadores e congrega milhares de profissionais: médicos, psicólogos, enfermeiros, terapeutas ocupacionais, fisioterapeutas, assistentes sociais e outros. O Sistema Conselhos de Psicologia tem participado recorrentemente dos congressos e manifestações da ABRASME, sendo que a categoria de psicólogos é muito forte nessa associação, a qual tem se manifestado cotidianamente contra a precarização do atendimento em saúde mental e defendido a expansão da rede de atenção pública e multiprofissional, com o aumento dos Centros de Atenção Psicossocial (CAPs). Tem criticado, também, as comunidades terapêuticas que atendem usuários de drogas, acusando-lhes de segregar as pessoas pelo emprego de subsídios financeiros das políticas públicas, destinados às entidades filantrópicas.

O CEBES nasce, em outubro de 1979, defendendo o reconhecimento do direito universal e inalienável à saúde. Há psicólogos que fazem parte desse centro e também estão ligados ao Sistema Conselhos de Psicologia. Além de atuarem no Centro de Estudos Brasileiros de Saúde, os psicólogos também participam da Associação Brasileira de Saúde Coletiva (ABRASCO), que nasce em 13 de novembro de 2011 com o objetivo de atuar na articulação entre formação, ensino e pesquisa em Saúde Coletiva para ampliação do diálogo com a comunidade técnico-científica e dos serviços de saúde. A ABRASCO teve, juntamente com o CEBES, intensa participação na VIII Conferência Nacional de Saúde, com a criação do Sistema Único de Saúde, aprovado a partir da promulgação da Constituição de 1988.

A Associação Brasileira de Psicologia Escolar e Educacional (ABRAPEE) foi fundada em 1990 por um grupo de psicólogos interessados em congregar os profissionais participantes da área, visando ao reconhecimento legal da presença do psicólogo escolar no ensino e na divulgação das pesquisas na Psicologia escolar e educacional. É uma organização sem fins lucrativos, que enfoca o processo educacional mais amplo, com vistas a problematizar a medicalização da educação. A ABRAPEE, juntamente com a Associação Brasileira de Ensino em Psicologia 
(ABEP), construiu um intenso trabalho de resistência à medicalização da educação, em muitas frentes políticas, acadêmicas, em fóruns e bases dos movimentos sociais.

A Psicologia também vem, segundo Dias et al. (2007), inserindo-se no campo da bioética e em outros trabalhos que atravessam a política de saúde brasileira, em diferentes facetas, contribuindo imensamente em associações, movimentos sociais e conselhos profissionais para a crítica à intensificação da medicalização dos corpos. Preocupa-se e se interessa por todos os temas sociais, como violência, pobreza, meio ambiente, educação e saúde, oferecendo grandes contribuições para notáveis preocupações do homem e da sociedade. Posiciona-se a propósito de discussões variadas da bioética. A preocupação com a biossegurança e a bioética é acionada pela busca de uma seguridade biológica e pela regulação ética dos limites das tecnologias, nos efeitos que poderão gerar. A extensão das biotecnologias propiciou intensa prática de cuidado, a produção de novos tratamentos, vacinas, cirurgias, medicamentos, terapêuticas variadas; mas não pode ser aceita sem cautela como uma solução mágica e um produto no mercado de patentes e inovação; é necessária uma postura crítica diante das intervenções e racionalidades que coloca em jogo em sua emergência.

Com efeito, a inserção de psicólogos tem crescido, nas associações, nos movimentos sociais e nas entidades profissionais que defendem o SUS, os quais criticam a medicalização na saúde mental, na saúde coletiva, na educação, na assistência social, no âmbito do judiciário e do executivo, na privatização das políticas públicas, na universidade, nos conselhos e comitês de representação, nas conferências de direitos e no Legislativo, nas manifestações escritas e nas ruas, bem como nas diferentes mídias.

\section{Considerações finais}

Vale ressaltar o quanto foi importante uma intensa participação coletiva de cunho popular, seja de muitos integrantes dos movimentos e instituições referidas neste texto, seja de outros grupos como, por exemplo, os comitês, os conselhos de saúde, as conferências nacionais e as diversas representações relevantes para a reivindicação, formulação de propostas e acompanhamento das políticas públicas de saúde mental e coletiva. Psicólogos e psicólogas estiveram presentes nessas resistências, deixando a marca das contribuições das psicologias e dos processos de resistência às práticas medicalizantes da existência.

As intervenções e iniciativas são intensas e sustentadas pela força política da grande participação de muitas entidades signatárias de boa parte dos documentos dos fóruns e associações citadas neste artigo, entre outras. A relação com a universidade, com partidos políticos, com movimentos internacionais e organismos multilaterais opera uma significativa pressão. Efetivamente, os movimentos que operam pela medicalização se sentem ameaçados, assim como a indústria farmacêutica e o empresariado da saúde e da educação. Esses grupos e empresas também realizam contrapoderes, visando silenciar e impedir uma crítica à medicalização da existência. Assim, criam igualmente manifestos e dialogam nos congressos, fazendo lobby no legislativo, no executivo e no judiciário.

As lutas não cessam, e a presença da Psicologia tem possibilitado um deslocamento na própria área, nas práticas profissionais e de pesquisadores. Todavia, os saberes e poderes em jogo continuam a acionar, por meio de variados equipamentos, leis, arquiteturas, tratados, normas e prescrições medicalizantes. Dessa maneira, as batalhas precisam de aquecimento com mais agenciamentos políticos, interferindo nos saberes, nos poderes e na constituição de subjetividades.

Assim, a inserção de psicólogos tem crescido, nas associações, nos movimentos sociais e nas entidades profissionais, os quais criticam a medicalização na saúde mental coletiva, na educação, na assistência social, no âmbito do judiciário e do executivo, na universidade, nos conselhos e comitês, nas conferências de direitos, nas manifestações escritas e nas diferentes mídias. Contudo, partindo das resistências do presente, é possível rastrear que estas se articulam historicamente, de maneira não linear, a diferentes práticas anteriores e, desse modo, atualizam novas configurações medicalizantes em redes mais duras e com tendências hegemônicas.

\section{Informações sobre as autoras:}

\section{Flávia Cristina Silveira Lemos \\ (iD) https://orcid.org/0000-0002-6601-0653 \\ (9) http://lattes.cnpq.br/8132595498104759 \\ Dolores Galindo \\ (iD) https://orcid.org/0000-0003-2071-3967 \\ (9) http://lattes.cnpq.br/6781116835399339}

Possui graduação em Psicologia/UNESP (1999). Licenciada em Pedagogia/CESB-GO (2017). Especialista em Psicopedagogia Clínica e Institucional/UNEB (2017). Mestre em Psicologia e Sociedade/ UNESP (2003). Doutora em História Cultural/UNESP (2007). Realizou pós-doutorado em Psicologia e Subjetividade, na UFF, sob supervisão da Profa. Dra. Maria Lívia Nascimento, em 2016.

Possui Pós-Doutorado (2015-2016), Doutorado (2006) e mestrado (2002) em Psicologia Social pela Universidade Católica de São Paulo (PUCSP), com Doutorado Sanduíche na Universidade Autônoma de Barcelona (2004). Graduada em Psicologia pela Universidade Federal de Pernambuco (UFPE), em 1999.

\section{Renata Vilela Rodrigues}

(iD) https://orcid.org/0000-0001-9181-6838

\section{(9) http://lattes.cnpq.br/1638956005245707}

Mestra em Estudos de Cultura Contemporânea pelo Programa de Pós-graduação em Estudos de Cultura Contemporânea (ECCO), da Universidade Federal de Mato Grosso (2015), com bolsa CAPES. Graduada em Psicologia pela Universidade Federal de Mato Grosso (2013).

\section{Evelyn Tarcilda Almeida Ferreira \\ (iD) https://orcid.org/0000-0002-4876-9463 \\ (3) http://lattes.cnpq.br/6606863894660466}

Possui graduação em Psicologia (UFPA/2001), Especialização em Gestão com pessoas (CESUPA/2007) e Formação em Dinâmica dos Grupos (SBDG/2008), Mestra em Psicologia Social (UFPA/2015). Doutoranda em Psicologia pela UFPA. 


\section{Contribuições dos autores}

Todos os autores colaboraram ao longo do processo, desde a elaboração até a revisão final do manuscrito. Os autores aprovaram o manuscrito final para publicação.

\section{Como citar este artigo:}

\section{ABNT}

LEMOS, Flávia Cristina Silveira et al. Resistências frente à medicalização da existência. Fractal: Revista de Psicologia, Niterói, v. 31, n. 2, p. 158-164, maio/ago. 2019. https://doi. org/10.22409/1984-0292/v31i2/5567

\section{APA}

Lemos, F. C. S., Galindo, D., Rodrigues, R. V., \& Ferreira, E. T. (2019). Resistências frente à medicalização da existência. Fractal: Revista de Psicologia, 31(2), 158-164. doi:10.22409/1984-0292/ v31i2/5567

\section{Referências}

ANGELL, Marcia. A verdade sobre os laboratórios farmacêuticos: como nos enganam e o que fazer. São Paulo: Record, 2007.

CAPONI, Sandra. Biopolítica e medicalização dos anormais Physis, Rio de Janeiro, v. 19, n. 2, p. 529-549, 2009. http:// dx.doi.org/10.1590/S0103-73312009000200016

DIAS, Hericka Zogbi Jorge et al. Psicologia e bioética: diálogos. Psicologia Clínica. Rio de Janeiro, v. 19, n. 1, p. 125-135, 2007. http://dx.doi.org/10.1590/S010356652007000100009

FOUCAULT, Michel. Microfísica do poder (1975). Tradução de Roberto Machado. Petrópolis, RJ: Vozes, 1979.

FOUCAULT, Michel. História da Sexualidade: a vontade de saber (1976). Tradução de Maria Thereza da Costa Albuquerque e J. A. Guilhon Albuquerque. 13. ed. Rio de Janeiro: Graal, 1988. v. 1

FOUCAULT, Michel. Em Defesa da Sociedade (1975). Tradução de Maria Ermantina Galvão. São Paulo: Martins Fontes, 1999.

FOUCAULT, Michel. Segurança, território e população (1977). Tradução de Eduardo Brandão. São Paulo: Martins Fontes. 2008a.

FOUCAULT, Michel. O Nascimento da Biopolítica (1979). Tradução de Eduardo Brandão. São Paulo: Martins Fontes, 2008 b.

MARTINS, Anderson Luiz Barbosa. Biopsiquiatria e bioidentidade: política da subjetividade contemporânea. Psicol. Soc., v. 20, n. 3, p. 331-339, 2008. http://dx.doi.org/10.1590/ S0102-71822008000300003

MILLER, Peter; ROSE, Nikolas. Governando o presente: gerenciamento da vida econômica, social e pessoal (2008). Tradução de Paulo Ferreira Valerio. São Paulo: Paulus, 2012.

NOGUEIRA, Roberto Passos. A segunda crítica social da Saúde de Ivan Illich. Interface (Botucatu), Botucatu, v. 7, n. 12, p. 185-190, 2003. http://dx.doi.org/10.1590/S141432832003000100022

NOVAS, C. The political economy of hope: patients' organizations, science and biovalue. BioSocieties, v. 1, n. 3, p. 289-305, Sept. 2006. https://doi.org/10.1017/ S1745855206003024
ORTEGA, Francisco. O corpo incerto: corporeidade, tecnologias médicas e cultura contemporânea. Rio de Janeiro: Garamond, 2008.

ROSE, Nikolas. A política da própria vida: biomedicina, poder e subjetividade no século XXI (2007). Tradução de Paulo Ferreira Valerio. São Paulo: Paulus, 2013. 